\title{
A EXPERIÊNCIA DO NÚCLEO DE ESTUDOS DE MEIOS DE SOLUÇÃO DE CONFLITOS (NEMESC)
}

Carlos Alberto de Salles, Daniela M. Gabbay, Erica B. Silva, Fernanda Tartuce, Luis Fernando Guerrero e Marco Antônio G. L. Lorencini

\section{RESUMO}

O ARTIGO APRESENTA A EXPERIÊNCIA DESENVOLVIDA PELO Núcleo de Estudos de Meios de Solução de Conflitos (NEMESC) No ÂMBITO DA FACULdAdE DE DIREITO DA Universidade de São Paulo. As atividades desenvolvidas, QUE COMPLETARAM CINCO ANOS EM 2009, TIVERAM INÍCIO INFORMALMENTE ATRAVÉS DE GRUPO DE ESTUDO COM ALUNOS DA GRADUACÃO E PÓS-GRADUACÃO E HOJE SE FIRMARAM COMO Disciplinas de EXTENSÃo da Faculdade de DiReito. Este ARTIGO CONSIDERA AS ATIVIDADES E PRÁTICAS DESENVOLVIDAS PELO GRUPO, AS ESCOLHAS METODOLÓGICAS E O ENVOLVIMENTO DOS ALUNOS DURANTE ESTES CINCO ANOS DE EXPERIÊNCIA DO NEMESC, PARA DEMONSTRAR OS RESULTADOS AUFERIDOS. O OBJETIVO É CONTRIBUIR PARA O DEBATE SOBRE O TEMA E UMA TROCA DE EXPERIÊNCIAS SOBRE MEIOS DE SOLUÇÃO DE CONFLITOS NO ÂMBITO DA FACULDADE DE DIREITO.

\section{PALAVRAS-CHAVE}

MEIOS ALTERNATIVOS DE SOLUÇ̃̃ DE CONTROVÉRSIAS; ATIVIDADES DESENVOLVIDAS PELO NEMESC; TROCA DE EXPERIÊNCIAS.

\section{ABSTRACT}

THIS PAPER PRESENTS THE 5 YEARS' EXPERIENCE OF THE alternative Dispute Resolution Group (NEMESC) established at the University of SaO PaUlo LaW SCHOOL. THE NEMESC BEGUN AS A STUDYING AND READING GROUP INTERESTED TO DEBATE AND TO RESEARCH ABOUT ALTERNATIVE DISPUTE RESOLUTION ISSUES, AND NOW A COURSE EMERGED FROM THIS STUDYING GROUP AT THE LAW SCHOOL. THIS PAPER CONSIDERS THE ACTIVITIES AND PRACTICES DEVELOPED BY THE GROUP, THE METHODOLOGICAL CHOICES AND STUDENTS INVOLVEMENT DURING THE 5 YEARS OF THE NEMESC EXPERIENCE TO SHOW SOME POSITIVE RESULTS. THE PAPER GOAL IS CONTRIBUTING TO THE DEBATES ABOUT ALTERNATIVE DISPUTE RESOLUTION AND TO THE EXCHANGE OF VIEWS AND EXPERIENCES ABOUT ADR AT THE LAW SCHOOL ENVIRONMENT.

\section{KEYWORDS}

ALTERNATIVE DISPUTE RESOLUTION; ACTIVITIES AND PRACTICES DEVELOPED BY THE NEMESC GROUP THE EXCHANGE OF EXPERIENCES.

\section{INTRODUÇÃO}

A necessidade é a mãe da inovação. Essa frase, atribuída a Platão, já foi por muito tempo tomada e repetida como uma das grandes verdades da humanidade. Premido pela necessidade, o ser humano é capaz de superar dificuldades e criar soluções, deixando para trás limites muitas vezes tidos como insuperáveis. Hoje, essa afirmação certamente está em xeque. Afinal, na era da revolução tecnológica, a inovação frequentemente vem antes, a necessidade, depois. 
Criam-se aparelhos, equipamentos e programas de computador que nossos pais sequer ousariam imaginar e dos quais jamais precisaram. Em pouco tempo, saímos por aí dizendo que não viveríamos sem tais aparelhos, para em poucos meses abandoná-los em troca de outros ainda mais atuais e sofisticados. Não que essas invenções não sejam proveitosas e não signifiquem ganhos de produtividade e conforto, mas, invertendo a lógica anteriormente dominante, a inovação vem antes, criando necessidades até então inexistentes.

De todo modo, a força motriz da necessidade continua presente e prossegue alimentando a inventividade humana na constante busca de soluções para seus problemas

O chamado Núcleo de Estudos de Meios de Solução de Conflitos, ou simplesmente NEMESC, que funciona junto ao Departamento de Direito Processual da USP, nasceu assim, despretensiosamente, para atender a uma necessidade imediata, e acabou crescendo na busca de solucionar outras necessidades, surgidas em sua trajetória de crescimento.

Em 2005, no curso de Teoria Geral do Processo, do segundo ano da Faculdade de Direito da USP, ministrado pelo professor Carlos Alberto de Salles, fez-se sentir a necessidade de um espaço no qual fosse possível ir além das fronteiras tradicionais de nosso direito processual civil. Sob a iniciativa desse professor, decidiu-se levar ao aluno um universo estranho àquele dos manuais e currículos das faculdades de direito brasileiras. Em meio à intensa crise vivida pelo judiciário nacional, submerso em uma quantidade de processos muito maior do que a sua capacidade de vazão, ficava estranho ensinar aos alunos aquele processo de base estatal e judicial, como se nada estivesse acontecendo e não houvesse outras soluções a serem discutidas.

A necessidade surgida, então, era buscar alternativas, formas de mostrar aos alunos outros horizontes, que, embora bem conhecidos no plano internacional, ainda patinavam - e patinam - em sua entrada na cultura e na prática jurídica brasileira. Tinha-se por ponto de partida a inevitável conclusão de que mecanismos diversos daqueles estudados nas aulas de processo poderiam dar respostas tão ou mais eficientes para a solução de disputas surgidas na vida das pessoas ou no andamento de negócios.

Em resposta a essa necessidade, surgiu a ideia de um seminário extracurricular, a ser realizado fora do período das aulas e aberto, como atividade voluntária, a todos os alunos do curso de Teoria Geral do Processo. Nessa iniciativa didática, não queríamos, é claro, repetir mais uma vez a enfadonha rotina das aulas expositivas ou dos seminários teóricos, tão bem conhecida dos cursos de direito. Desse tipo de atividade, o currículo escolar já estava cheio, e outras experiências de seminários extracurriculares já haviam sido realizadas.

Fugindo ao perfil tradicional dos cursos de direito, nossa avaliação dava conta de uma atávica falta de atividades práticas que importassem em uma vivência concreta por parte dos alunos. Por essa razão, a palavra orientadora dessa iniciativa foi vivencial: 
queríamos uma atividade capaz de direcionar o aluno a vivenciar uma atividade prática, concreta mesmo. Evidentemente, apenas vivência também não interessava, pois estávamos trabalhando em um campo pouquíssimo conhecido, estranho à matéria estudada em sala de aula, fazendo-se necessário, então, formar um mínimo de "massa crítica” para uma correta apreensão e compreensão da realidade a ser experimentada pelos alunos.

Firmadas essas premissas, ainda que de maneira inteiramente espontânea, ordenamos nossa atividade em alguns seminários teóricos, organizados a partir de textos indicados para leitura e discussão em grupos pequenos e visitas que os alunos deveriam realizar ao final, utilizando um formulário de orientação a ser preenchido.

No primeiro semestre, propusemo-nos a trabalhar com mecanismos alternativos de solução de controvérsias, os chamados - no âmbito internacional Alternative Dispute Resolution (ADR). Até por falta de acesso a outras experiências, ${ }^{1}$ a atividade "vivencial” seria realizada junto aos setores de conciliação instalados no poder judiciário.

No segundo semestre, nossa intenção era trabalhar com arbitragem, mas o modelo adotado no primeiro semestre precisou ser revisto. Sim, pois, embora não seja uma imposição legal, as arbitragens no Brasil costumam ser confidenciais, por disposição das partes e/ou previsão nos regulamentos das instituições onde são realizadas. Isso inviabilizava o modelo de visitas adotado em relação à conciliação, já que os alunos não poderiam acompanhar o desenvolvimento das atividades arbitrais.

Novamente a necessidade foi a mãe, e surgiu a ideia de realizarmos uma arbitragem simulada, como recurso didático para propiciar ao aluno aquela prática vivencial por nós ambicionada. Assim, até porque estávamos trabalhando com alunos de segundo ano do curso de graduação, mantivemos os seminários teóricos, para apresentação das principais ideias e do modo de funcionamento da arbitragem, como uma espécie de preparação da simulação a ser realizada ao final.

Essas atividades, cujo início descrevemos acima, completaram em 2009 o seu quinto ano de existência. As energias despendidas e a atração exercida pelas atividades foram de tal ordem positivas que acabaram por se institucionalizar no NEMESC e em duas disciplinas de cultura e extensão regularmente oferecidas. A partir das necessidades surgidas em uma singela atividade extracurricular, foi possível localizar outras e criar um espaço de diálogo e debate para aquelas pessoas que, na comunidade acadêmica da USP, buscam alternativas àquelas concepções mais tradicionais de processo.

Um importante "filhote" das atividades descritas foi um grupo de estudos integrado pelos estudantes de pós-graduação que colaboram com a orientação e desenvolvimento das atividades da graduação. Esse grupo, que se reúne com razoável periodicidade, já patrocinou um interessante projeto, com a participação interinstitucional do professor William dos Santos Ferreira (PUC-SP), de estudo de modelos de processo civil, tentando realizar a comparação de soluções adotadas em vários países em termos de regulamentação da prestação jurisdicional do Estado. 
Foi a atividade junto aos alunos de graduação, no entanto, a geradora do maior número de experiências, dificuldades e soluções e que o presente artigo se propõe a descrever, com o objetivo de compartilhar o conhecimento adquirido e propiciar o surgimento de outras iniciativas como esta aqui debatida.

Alguns pontos merecem destaque, para permitir a correta compreensão do enquadramento institucional dos itens desenvolvidos na sequência. Em primeiro lugar, há de se destacar que atualmente as atividades descritas estão formalizadas como disciplinas de cultura e extensão. Na verdade, três disciplinas: uma relativa ao programa de conciliação e mediação, realizado no primeiro semestre letivo do ano; outra concernente às atividades de arbitragem, desenvolvida no segundo semestre; e, ainda, uma terceira, de monitoria, que permite aos alunos egressos das disciplinas colaborarem como monitores em seu desenvolvimento junto a outras turmas, em uma ideia de aprofundamento e continuidade.

Esse formato - de disciplina de extensão - ao qual se chegou depois de alguns anos de busca acabou se mostrando bastante funcional. Resolve a necessidade de oficializar a atividade, permitindo ao aluno ter em seu histórico escolar o registro de sua participação. Ademais, não incorre nas dificuldades de uma disciplina regular do curso de graduação, com problemas, quase incontornáveis, como o de sua inclusão em uma grade já saturada, o de critérios formais de avaliação e o de disputa de horário no período oficial de aulas, entre outros, além de permitir mais facilmente a participação de alunos de pós-graduação na coordenação das atividades.

Como disciplina de extensão, todavia, enfrenta a dificuldade de divulgação entre os alunos, ainda mais por se tratar de um tema novo, e de disputar espaço com outras atividades oferecidas a eles. Como na Faculdade de Direito da USP os professores de processo acompanham a turma, o vínculo originalmente existente com as disciplinas regulares de processo, ${ }^{2}$ para as quais o seminário extracurricular foi concebido, perdeu-se.

A esse propósito, um fato tem se verificado ao longo do desenvolvimento do programa: uma maior procura pela disciplina de extensão de arbitragem e uma menor por aquela de conciliação e mediação. A explicação que encontramos é significativa do estado da arte desse tipo de abordagem em nossas faculdades de direito. Essa preferência ocorre provavelmente porque o aluno se identifica mais com os papéis desempenhados pelo advogado na arbitragem, que não deixa de ser um procedimento de adjudicação, desenvolvido de forma adversarial. Em razão de condicionantes culturais, o aluno não se vê com facilidade incorporando papéis ligados a um advogado o qual atua em soluções consensuais de controvérsias, embora seu papel nessas também possa ser primordial.

Esse condicionamento cultural precisa mudar, pois, como temos insistido com nossos alunos, no universo de todos os conflitos surgidos na sociedade, a grande maioria deles é resolvida consensualmente, por negociação direta entre as partes ou 
com o auxílio de terceira pessoa. O profissional de direito precisa e deve ter uma inserção positiva nesse universo. Ademais, é facilmente compreensível que, antes de se chegar às vias adjudicatórias - arbitragem ou poder judiciário -, esgotem-se as vias de solução consensual da controvérsia.

Com esse objetivo, o NEMESC tem se esforçado para dar maior visibilidade à disciplina de cultura e extensão ligada à conciliação e à mediação, realizada no primeiro semestre de cada ano. Nos últimos dois anos, têm sido desenvolvidas, também, atividades de mediação simulada ao término dos seminários teóricos. $\mathrm{Na}$ edição de 2009, chegou a ser apresentada uma peça teatral descrevendo a realização de uma mediação. ${ }^{3}$ Tudo isso visa a suprir o contraste entre os seminários teóricos, em grande parte baseados em autores estrangeiros, e a realidade encontrada pelos alunos nos setores de conciliação visitados. Um aluno chegou a dizer que essa era a única disciplina na qual a teoria era melhor do que a prática.

Os itens seguintes buscam mostrar de forma mais detalhada as atividades desenvolvidas e a experiência acumulada.

O objetivo dos autores do presente artigo é compartilhar essa experiência, com a deliberada intenção de gerar emulação. Atingiremos nossos objetivos se nossa iniciativa for imitada e se novas experiências puderem se somar ao debate público das questões aqui envolvidas. Afinal, temos clara a importância da modificação da cultura dos profissionais do direito em relação às formas de solução de conflitos e controvérsias. O caminho, para tanto, passa necessariamente pelas faculdades de direito. Fica aqui nosso convite e incentivo para que novas iniciativas, em outras instituições de ensino, sejam tomadas.

\section{Proposta metodológica}

Esta segunda parte do artigo trata das escolhas metodológicas realizadas pelo NEMESC na montagem dos cursos de extensão de mediação, conciliação e arbitragem. Essas escolhas estão em constante análise e mudança (uma das vantagens do curso de extensão é a sua flexibilidade curricular permitir experimentações), mas algumas diretrizes metodológicas, notadamente aquelas que visam contribuir para uma visão não contenciosa do conflito pelos alunos, são permanentes. Tais diretrizes são expostas a seguir.

\section{I Por QUe No Iní́cio do CURSo De DiReito?}

O público-alvo dos dois cursos de extensão (mediação e conciliação, no primeiro semestre, e arbitragem, no segundo) é composto preferencialmente por alunos do segundo ano do curso de direito - muito embora sejam admitidos alunos de outros períodos interessados nas atividades. A opção de desenvolver essas atividades de mediação, conciliação e arbitragem no início do curso tem por objetivo sensibilizar 
o aluno sobre as formas alternativas de solução de conflitos em um momento de formação no qual ele ainda não teve grande contato (quer academicamente, quer por meio de estágios profissionais) com o poder judiciário e as formas adjudicatórias de solução de conflitos.

Ao invés de aguardar até o último ano do curso de direito para oferecer disciplinas optativas relacionadas aos meios alternativos de solução de conflitos, a ideia do NEMESC é inversa: oferecer ao aluno disciplinas de extensão sobre os meios alternativos de solução de conflitos no início do curso, para que as técnicas compositivas tratadas não tenham como eixo gravitacional o judiciário e seus eventuais problemas, mas sim os conflitos e os interesses das partes envolvidas, agregando à teoria geral do processo uma teoria geral do conflito que considere as variadas possibilidades de seu processamento e solução.

Trata-se de um movimento positivo de construção - e não de desconstrução de uma mentalidade já formada. Com isso, não se quer dizer que o judiciário deva ser evitado ou visto como a última alternativa possível, pois se sabe que um bom funcionamento de outras técnicas compositivas depende de um judiciário eficiente, e há demandas que devem considerá-lo como a primeira - e às vezes exclusiva - alternativa possível. Todavia, não há nada melhor do que se deparar com diferentes métodos compositivos para contrastar as potencialidades e limitações de cada um, o que é mais difícil de perceber quando há a imersão em um único método. O objetivo é, portanto, ampliar as perspectivas do aluno ao confrontá-lo com um mapa mais variado de formas de se processar e solucionar conflitos.

Essa é uma tendência em expansão em outros países. Nas escolas de direito norte-americanas, por exemplo, muitos dos cursos apresentam logo no início, em sua grade curricular, a disciplina de meios alternativos de solução de conflitos (Alternative Dispute Resolution) ou mesmo clínicas de mediação, em que os alunos são expostos a técnicas autocompositivas diante de casos e problemas reais. Segundo Bryant Garth, a melhor forma de criar uma conexão entre o processo civil e os meios de solução de conflitos alternativos seria estes últimos trazerem uma nova perspectiva ao processo civil tradicional, aproximando tais campos de conhecimento. ${ }^{4}$

\subsection{RelaÇÃo ENTRE TEORIA E PRÁtica}

Nos cursos de mediação, conciliação e arbitragem, adotou-se a dinâmica de seminários, nos quais são discutidos alguns temas em reuniões semanais com os alunos durante a primeira parte do semestre, combinada com uma parte prática e vivencial subsequente, em que os alunos são expostos à dinâmica vivencial, quer através de visitas a setores de conciliação, quer através de simulação de mediação e arbitragem, em que recebem um caso concreto para atuar nos moldes do que ocorre realmente (na mediação, com a participação de mediadores orientando a prática dos alunos; na arbitragem, com árbitros convidados para compor o painel arbitral). 
Neste binômio teoria-prática, os alunos têm a possibilidade de testar e contextualizar os conceitos aprendidos através de uma experiência concreta relevante ao seu aprendizado.

\subsection{Parte teórica - Seminários}

Para os seminários, os alunos recebem uma lista de textos para leitura prévia que irá guiar os debates nos encontros (com periodicidade semanal). Nesses encontros, os textos são então debatidos com monitores de graduação e pós-graduação, mediadores do debate.

A lista de textos é selecionada e revista a cada ano, considerando a qualidade dos debates gerados e o feedback dos alunos sobre os textos. Normalmente são incluídos textos favoráveis e também contrários aos meios de solução de conflitos alternativos ao judiciário. O ideal é que os grupos dos seminários sejam pequenos, para que se forme uma mesa redonda na qual os alunos se sintam à vontade para expor argumentos sobre o texto em discussão.

O objetivo central desta fase do curso é formar massa crítica, essencial à qualidade da participação dos alunos na parte prática das atividades do NEMESC.

\subsubsection{Parte Prática}

\subsubsection{Mediação e conciliação}

A parte prática da disciplina consiste em visitar setores de conciliação do Tribunal de Justiça do Estado de São Paulo (em primeira e segunda instância) e participar de mediações simuladas.

Conforme se verá com detalhes na parte 3 deste artigo, foi preparado para esta atividade um formulário, entregue aos alunos para preenchimento durante as visitas, com um espaço livre, destinado às observações e impressões subjetivas sobre as sessões de conciliações vistas. ${ }^{5}$ Esse formulário visa guiar as visitas, e seu preenchimento produz um material empírico muito rico gerado a partir do contato dos alunos com a realidade após alguns meses de debates e seminários teóricos sobre mediação e conciliação.

Além das visitas, outras atividades práticas também foram realizadas durante o curso de extensão de mediação e conciliação, como simulações de mediação, e, no ano de 2009, pela primeira vez, uma leitura dramática teatral sobre a realização de mediação, assistida pelos alunos ao final do curso. Estas atividades serão tratadas com mais detalhes na parte 3 deste artigo.

\subsubsection{Arbitragem}

A parte prática da arbitragem visa simular um processo arbitral. Os alunos recebem um caso, assumem diferentes papéis e atribuições, redigem documentos e se preparam para um painel arbitral em que sustentam oralmente suas razões perante um painel de 
três árbitros (escolhidos entre professores que aliam sua experiência docente à atuação em painéis arbitrais reais).

O papel didático dessa simulação é muito relevante. Além de reproduzir o que potencialmente ocorre em um caso real (algo difícil de o aluno presenciar, em face do sigilo que normalmente reveste os processos arbitrais), os árbitros-professores adotam postura pedagógica importante, ao pausar a simulação para explicações e esclarecimentos sobre os desenrolar do caso e do julgamento.

Trata-se de um formato em que o aluno aprende fazendo, além de desenvolver variadas habilidades através da simulação, como a redação de peças, trabalho em grupo, pesquisa, definição de estratégias, atuação e defesa oral dos argumentos no painel arbitral, entre outras habilidades e competências. A Parte 4 do artigo tratará com mais detalhes dessa atividade.

\subsection{Avaliação}

A avaliação também é um momento muito importante nos cursos de extensão de mediação, conciliação e arbitragem, envolvendo os alunos e os monitores de graduação, pois ambos recebem créditos ao final dos cursos.

Nos seminários, os alunos são avaliados com base na assiduidade e na participação nos debates, enquanto na parte prática há outras ferramentas avaliativas, como a entrega dos formulários preenchidos durante as visitas aos setores de conciliação e a avaliação da simulação da arbitragem no segundo semestre - redação das peças que compõem o processo arbitral e atuação no dia do painel arbitral, através da defesa oral dos argumentos diante do painel de árbitros.

Os monitores de graduação, por sua vez, são avaliados a partir da assiduidade e do gerenciamento das atividades no curso do semestre, com a participação e instigação dos debates nos seminários, apoio na aplicação dos exercícios práticos e condução das atividades em geral.

\subsection{Continuidade das atividades E DO APRENDizado}

O objetivo dos cursos de extensão do NEMESC é plantar uma semente nos alunos e sensibilizá-los, fazendo-os pensar o conflito a partir de diferentes perspectivas, com o acesso a opções compositivas que não se restrinjam apenas ao judiciário. Os alunos que tiverem interesse em continuar e aprofundar esses estudos podem se inscrever para atuar como monitores de graduação do NEMESC nos semestres seguintes, o que viabiliza a continuidade na troca de experiências e debates sobre mediação, conciliação e arbitragem, sendo os alunos verdadeiros multiplicadores das atividades desenvolvidas junto ao NEMESC.

No futuro, objetiva-se também desenvolver projetos de pesquisa relacionados às atividades do NEMESC, envolvendo alunos da graduação e pós-graduação em torno da temática de meios de solução de conflitos. 


\section{Meios alternativos de soluções de Controvérsias: MEDIAÇÃO E CONCILIAÇÃO}

A disciplina é desenvolvida com vistas a proporcionar uma nova e diferenciada visão aos alunos sobre as possibilidades de enfrentamento de conflitos. Conhecendo e compreendendo as várias técnicas de composição, é possível refletir sobre qual saída apropriada é mais próxima de uma solução genuinamente pacificadora da controvérsia (em contraposição à solução contenciosa decorrente do sistema adjudicatório pelo poder judiciário, que pode acabar fomentando mais crises). Pretende-se, através do estudo sobre diversos mecanismos de resolução de conflitos, ensejar uma formação mais completa aos profissionais do direito. Na qualidade de gestores de conflitos, é importante o despertar de sua sensibilidade a diversificadas possibilidades: os vários meios de composição de controvérsias, inclusive de cunho consensual, são importantes ferramentas para operar a transformação e a superação dos impasses. As atividades do NEMESC visam propiciar uma experiência teórica e prática sobre o assunto.

Para tanto, a análise se verifica sob a perspectiva de uma (desejável) "teoria geral dos meios apropriados de composição de conflitos”, enfocando dois momentos, duas partes distintas de contato com os temas. A primeira parte é preponderantemente teórica, favorecendo a análise de conceitos e classificações por meio de leituras individuais e debates em sala de aula. A segunda é voltada à vivência, com a realização de mediações simuladas e pesquisa de campo em instituições judiciárias.

\section{I Primeira parte - teoria: leituras e debates}

A despeito de os estudos clássicos do curso de graduação não dedicarem tempo e atenção à construção do consenso, na prática, o bacharel, ao perceber a atuação forense, irá se defrontar com inúmeras ocasiões em que a busca do consenso será necessária. ${ }^{6}$ Há inúmeras circunstâncias, no processo civil, em que o magistrado dará azo ao seu dever de conciliar as partes ${ }^{7}$ Como irá se portar o operador do direito em tal oportunidade, se em seus estudos jamais teve contato aprofundado com os meandros de tal possibilidade?

Ao se inscreverem para a disciplina de extensão, os alunos precisam indicar seus endereços eletrônicos, porque a comunicação e a transmissão de informações ocorrem essencialmente pela via digital. Algumas semanas antes do início das aulas, os alunos recebem por email o cronograma do curso, que aponta os conteúdos das aulas e as leituras a serem realizadas sobre cada tema ${ }^{8}$ afinal, no desenvolvimento da primeira parte do semestre, para que os alunos possam ter contato com conceitos e categorizações, há uma indicação bibliográfica de textos especialmente selecionados para tal.

A primeira aula é lecionada pelo professor Carlos Alberto de Salles. Após abordar as propostas do NEMESC, o professor salienta que a proposta de aprendizado é diferenciada e demanda a intensa participação dos alunos; para tanto, os alunos e os 
condutores da disciplina posicionam-se sentados em um grande círculo. Após o primeiro contato, o professor realiza um overview sobre os temas que serão posteriormente desenvolvidos; geralmente é indicado um texto de leitura prévia, para que os alunos possam comentar suas primeiras impressões sobre o assunto, e os debates já ocorrem logo no início do curso.

Após a aula inaugural, os demais textos serão abordados em quatro seminários de uma hora e meia cada um. ${ }^{9}$ No cronograma, já constam desde o início os textos a serem lidos; seu número pode variar de dois a quatro textos obrigatórios, a depender do tema. ${ }^{10} \mathrm{~A}$ finalidade é familiarizar os alunos com conceitos basilares, despertando seu olhar para características dos conflitos, melhores técnicas para enfrentá-los, diferença entre os meios e quando são ou não recomendáveis. Muitas vezes, a discussão dos temas é paralisada pela necessidade de sanar dúvidas que surgiram quando da leitura individual ou para diferenciar a experiência consensual do padrão estudado no sistema contencioso geralmente abordado nas disciplinas regulares de graduação.

Muito embora os meios diferenciados sejam constantemente apresentados como alternativas ao crescimento vertiginoso dos conflitos contenciosos, destaca-se desde o inicio dos estudos que uma visão meramente utilitarista não se revela adequada. Afinal, a principal vantagem da utilização dos meios alternativos não é propriamente a redução do número de ações pendentes de julgamento, mas sim o potencial e efetivo alcance da pacificação social, pela qualidade do resultado que eles podem ensejar. Com isso, busca-se favorecer o desenvolvimento do senso crítico dos alunos, os quais terão mais subsídios para identificar as mais adequadas formas de composição dos conflitos intersubjetivos.

Assim, mais do que apenas apresentar as ferramentas, a tônica é mostrar que a busca pelo mecanismo deve considerar a busca do meio mais apropriado para atender aos anseios dos litigantes rumo a uma efetiva pacificação.

\subsection{SEgUNDA PARTE - VIVÊNCIAS: MEDIAÇÕES SIMULADAS E PESQUISA DE CAMPO SOBRE CONCILIAÇÃO}

Após quatro aulas de conteúdo teórico, são realizadas atividades práticas, dando inicio à segunda parte dos estudos. Por meio da vivência, permite-se a concreta utilização dos conhecimentos teóricos, para melhor identificar e solucionar problemas jurídicos a partir de casos, instigando a criatividade interpretativa e a análise crítica da matéria estudada.

\subsection{Mediação simulada}

Esta atividade busca traduzir exemplos da práxis existente; para tanto, evidencia-se a relevância da mediação simulada, em que os alunos, em um primeiro momento, são colocados em uma aparente situação de conflito, a fim de que possam desempenhar de maneira mais efetiva os conhecimentos adquiridos. 
Ao longo dos anos, foram adotadas diversas modalidades de mediação simulada. A primeira experiência funcionou por role play, em que uma mediadora convidada fez a mediação entre uma dupla de litigantes (representados por alunos), pausando o procedimento oportunamente para comentários e observações dos discentes.

No ano seguinte, uma outra tentativa utilizou formato diverso. Os alunos foram reunidos em grupos de três: um deles atuava como mediador, e os demais figuravam como litigantes. Antes do início das mediações, porém, para facilitar sua performance, foi distribuído a todos um roteiro resgatando o passo a passo do procedimento da sessão de mediação.

Na sequência, foram determinados os grupos; os alunos dividiam entre si as funções de mediador e contendores. Aos alunos "mediandos" foi fornecido um script sigiloso, uma consigna com informações privilegiadas sobre motivações e outros elementos relevantes para a resistência de seu personagem. A professora e os monitores acompanhavam o desenvolvimento dos grupos como observadores e, após 45 minutos, os grupos eram desfeitos.

Havia, então, um debate geral sobre as percepções de cada aluno (para expor como se sentiu durante a experiência, as dificuldades vivenciadas etc.). Merece destaque o fato de que alguns alunos que protagonizavam litigantes, apesar de terem recebido informações privilegiadas por escrito sobre o perfil de seus personagens, acabavam ampliando elementos das crises, trazendo espontaneamente novos dados inicialmente não cogitados (o que, por vezes, trazia complicações ao mediador). Tal inserção pode, por um lado, significar envolvimento e criatividade dos alunos, e, por outro, revelar como a índole combativa e contenciosa está arraigada na percepção dos conflitos.

Em 2009, procurou-se realizar uma sequência mais intensa de atividades de simulação, contando com a especial participação de mediadoras convidadas.

A primeira experiência foi protagonizada por uma mediadora ${ }^{11}$ que dividiu os alunos em grupos e realizou dinâmica para que debatessem (primeiro entre si, depois para todos) sobre o conceito de mediação, seus princípios e o papel do mediador.

Após tal recapitulação, uma mediação teve início; nela, uma aluna foi a mediadora e dois alunos, os litigantes; ela e todos os demais foram observadores e comediadores, podendo fazer intervenções durante o procedimento. Os alunos "mediandos" receberam um script e comportaram-se conforme as premissas ali constantes. A aluna-mediadora falou primeiro com um litigante, e o outro aguardou separadamente, fora da sala. Conforme ela ia falando, a professora-mediadora e os demais alunos podiam interromper a sessão e fazer perguntas e observações. Embora interessante, a experiência teve o inconveniente da duração: foi muito longa, extrapolando o tempo geralmente destinado à reunião. Interessante destacar que o caso utilizado para a atividade estava relacionado à esfera civil, mas com diversos desdobramentos, por se tratar de uma relação continuada. 
$\mathrm{Na}$ sequência, foi realizada mais uma atividade, nos mesmos moldes da primeira, com a mediadora Célia Regina Zapparolli, que trouxe um caso de direito de família. Aqui cumpre destacar que, além da atuação dos alunos a partir de um script comum, cada parte recebeu também a distinção entre a sua posição e o seu interesse, bem como informações sigilosas das quais os demais participantes não tinham conhecimento. Isso permitiu aos alunos um exercício constante de reflexão sobre a importância da postura do mediador e sua linguagem.

\subsubsection{Pesquisa de Campo sobre Conciliação}

Após as atividades de mediação simulada, outra experiência prática é vivenciada na segunda parte do curso. Munidos das experiências amealhadas, os alunos realizam visitas a setores de conciliação em instituições judiciárias; em 2009, foram visitados o Setor de Conciliação do Foro Central da Comarca da Capital do Estado de São Paulo, o Setor de Conciliação do Tribunal de Justiça de São Paulo e, ainda, enfocando a esfera extrajudicial, o Setor Extrajudicial do Foro Central da Comarca de São Paulo. ${ }^{12}$

Os alunos devem se dirigir aos setores em dias e horários previamente marcados e assistir a algumas sessões de conciliação, coletando dados específicos sobre a experiência e anotando-os em um formulário previamente fornecido, como já dito. Essa pesquisa procura verificar a presença dos sempre mencionados contratempos que impedem uma prestação jurisdicional de qualidade, entre os quais é possível destacar como principais o tempo, os custos elevados, a formalidade e a burocracia na resolução dos conflitos judicializados.

A realização de uma análise empírica pode conduzir à verificação objetiva de elementos para aferir a idoneidade da conciliação como ferramenta de efetiva composição. Nesse sentido, são investigados os seguintes pontos: a) identificação do caso (com indicação das partes envolvidas e da natureza do conflito); b) perfil do conciliador (idade, formação e preparação para o exercício da função); c) dinâmica da sessão de conciliação (verificando a contribuição do conciliador, dos advogados, a propensão das partes para o acordo, a utilização do argumento da morosidade do judiciário, a utilização de regras para o procedimento e a influência do direito material); d) realização de acordo (existência, iniciativa da proposta, satisfação das partes após a audiência e aproximação de seus contornos em relação ao direito material).

Assim, os alunos podem perquirir a adequação da conciliação tal qual vem sendo atualmente realizada, sobretudo enfocando a capacidade do órgão de ouvir atentamente os fatos apresentados pelas partes, sua percepção das verdadeiras necessidades existentes e, por fim, a apresentação de respostas que correspondam às expectativas pessoais. Procura-se, enfim, constatar a realização de uma conciliação que não favoreça simplesmente o acordo, mas que de fato proporcione um adequado tratamento do conflito. 
Após as atividades de pesquisa individualmente realizadas em campo, há um último encontro no núcleo de estudos, no qual os alunos entregam os relatórios por escrito das visitas e falam um pouco da experiência vivenciada.

Os alunos destacaram observações que merecem transcrição:

(i) É frustrante perceber que instrumento tão valioso como a audiência conciliatória seja tão mal utilizado pelos conciliadores. (aluna C. P. S)

(ii) Ressalto a profunda diferença entre a conciliadora que atuou nas sessões do Fórum João Mendes, detentora de formação em psicologia e especificamente em mediação, e aquela que conduziu a audiência no Juizado Especial Central, com formação meramente jurídica. (aluna A. T. S.)

(iii) Com relação à forma de condução da audiência pelo conciliador, tenho a dizer que se deu sem grandes formalidades e dando prioridade para o debate entre as partes. (aluno J. M. A. M)

(iv) $\mathrm{O}$ que me chamou a atenção nesta sessão de conciliação foi como uma contribuição positiva dos advogados, quando tendentes à aceitação do acordo, pode influenciar efetivamente a chegada ao consenso. (aluna B. R. P.)

(v) Lamentável o advogado das partes não saber a real finalidade de uma conciliação. (aluna D. C. P.)

\subsubsection{Conexão Com arte e Cultura: leitura dramática}

Finalmente, em 2009, além das duas últimas experiências apontadas, houve, como dito, a apresentação de leitura dramática teatral sobre a realização de uma mediação, enfocando a expectativa das pessoas envolvidas e a atividade dos mediadores. ${ }^{13}$ A apresentação decorreu da adaptação de uma peça teatral cujo projeto originou-se de atividade científica:14 como trabalho de conclusão de curso de especialização sobre mediação, foi elaborado um roteiro e apresentada uma peça teatral. A atividade passou a ser um dos projetos sociais de uma organização não governamental e visa a permitir a divulgação e disseminação deste instrumento de composição.

O evento foi aberto ao público e contou com a presença de alunos e mediadores. Após a apresentação da leitura dramática, houve um debate sob a coordenação da atriz e mediadora Lia Sampaio, que convidou a participar do círculo de debates o professor Carlos Alberto de Salles, a professora Giselda Hironaka, ${ }^{15}$ a magistrada Valéria Lagrasta, ${ }^{16}$ além de monitores de pós graduação do NEMESC. 
A experiência foi muito rica e encerrou com grande proveito as atividades do semestre, concretizando de forma ainda mais intensa as profícuas vivências experimentadas durante o desenvolvimento das atividades.

\section{Simulações de arbitragens - EXPeriênCia do NEMESC}

\section{I Preparações do caso}

A atividade de arbitragem foi uma das primeiras que surgiu no bojo do grupo coordenado pelo professor Carlos Alberto de Salles, sempre com a preocupação de analisar novas abordagens do processo, bem como oferecer o ensino destas de modo completo, teórico e prático.

Não se pode dizer que a atividade de arbitragem tenha surgido do acaso, mas seu ponto culminante, a arbitragem simulada, certamente surgiu de uma necessidade prática. Todos gostariam que os alunos participantes não só aprendessem arbitragem, mas também pudessem vê-la na prática e aplicar conceitos aprendidos.

Contudo, a maioria dos procedimentos arbitrais é sigiloso, o que impede a visita dos alunos a instituições e o acompanhamento de audiências. Então, buscou-se criar um ambiente no qual os alunos pudessem aplicar na prática os conceitos aprendidos nas atividades teóricas sobre arbitragem. Assim, decidiu-se criar uma atividade simulada, contando com professores que já atuaram como árbitros.

Com a ideia embrionária do que seria tal simulação, passou-se a pensar nos tipos de questões que seriam passíveis de utilização, por parte dos alunos, nas atividades de aprendizado do funcionamento de uma arbitragem.

Inicialmente, causou embaraço o fato de os alunos estarem apenas no segundo ano letivo da faculdade de direito e não se saber até que ponto eles dominariam uma matéria de mérito do litígio posto, a ponto de defendê-la e discuti-la perante uma banca. A solução, contudo, foi arriscar, isto é, apresentar questões complexas para os alunos, simplificando-as onde fosse possível, e ajudá-los também naquilo que não fosse transferir o trabalho para terceiros.

Foi nessa esteira que os monitores surgiram, alunos mais velhos com algum conhecimento do assunto ou que já tinham participado da atividade em anos anteriores, sob a coordenação de alunos da pós-graduação.

A espinha dorsal do grupo, portanto, estava formada, e o anúncio da atividade foi feito para alunos do segundo ano letivo da faculdade de direito da Universidade de São Paulo no ano de 2005, com opção de dois dias semanais para que as atividades fossem realizadas. Na época, o professor Carlos Alberto de Salles era professor regente de Teoria Geral do Processo para os alunos que eram "os alvos" da atividade; assim, a adesão foi grande.

Passou-se, então, a discutir qual caso prático seria aplicado aos alunos. O objetivo foi traçado: em primeiro lugar, deveria ser um caso com discussão jurídica simplificada, 
com a consequente remoção de alguns detalhes, e, em segundo lugar, era preciso existir referências doutrinárias e jurisprudenciais para alicerçar qualquer um dos pontos que o grupo fosse defender. Nesse sentido, o caso prático partiu de um famoso caso envolvendo arbitragem no Brasil como pano de fundo de direito material.

A elaboração do caso é feita em duas fases. Primeiro, busca-se uma relação jurídica base, na maioria das vezes contratual, que facilita a vivência dos alunos com regras e legislações aplicáveis. Depois, cria-se um conflito decorrente dessa relação. Há sempre um inadimplemento, mas com discussões de culpabilidade e arbitrabilidade da questão discutida.

Regra geral, portanto, sempre há uma discussão prejudicial da arbitragem a qual envolve arbitrabilidade, análise das questões que podem ser submetidas à forma de solução de conflitos arbitral, e uma discussão de direito material com alguns aspectos fáticos nebulosos, para que os alunos possam criar (quanto à matéria probatória, por exemplo) e tentar convencer os árbitros que participarão do painel.

\subsection{DIVISÃo DE PAPÉIS}

Superadas essas fases, buscou-se também garantir aos alunos conhecimento acerca dos regulamentos de câmaras de arbitragem, com o fim de manejá-los e tomar decisões conforme as regras lá estabelecidas. Obviamente, na execução dos casos práticos, os regulamentos precisaram ser simplificados e alguns procedimentos foram extirpados, tendo em vista a exiguidade de tempo, elevada complexidade ou até mesmo irrelevância para o exercício prático proposto.

Desenvolvidas as monitorias, pretendeu-se incluir o maior número possível de alunos no painel arbitral, com a criação de diversos papéis, como os de peritos de várias matérias, testemunhas variadas e muitos advogados. Essa estratégia foi equivocada, já que o envolvimento dos alunos não ocorreu com a mesma profundidade e o painel mostrou-se mais longo do que os coordenadores do evento consideravam razoável.

Com base nessas experiências anteriores, hoje há uma participação mais enxuta: quatro alunos como advogados de cada uma das partes, um representando cada uma das partes e poucas testemunhas. Os painéis demonstraram que muitas testemunhas e muitos peritos acabavam deslocando o foco da atividade de um plano técnico para um plano teatral, que, embora interessante, não é o ponto principal da atividade.

A alteração de rumo se mostrou interessante, e a criatividade dos alunos levou à busca até de pareceres de professores acerca das questões envolvidas na simulação. Isso consolidou o entendimento de que a menor quantidade de alunos não significaria menor esforço e, principalmente, menor qualidade.

Viu-se, então, que a redução de alunos participantes concentrava a questão no âmbito técnico-jurídico e envolvia mais os alunos no caso, já que a divisão de trabalho era menor e permitia que eles acompanhassem uma parcela maior do processo criativo da atividade. 
Os árbitros, por sua vez, são escolhidos entre professores atuantes na área de arbitragem, bem como especialistas na matéria envolvida. Já foram árbitros das atividades diversos professores, mas sempre atendendo ao requisito da especialização, tão caro na arbitragem.

\section{3 $\operatorname{Casos}^{17}$}

Em 2005, o primeiro das atividades, o caso partiu de uma discussão envolvendo a vinda de uma montadora para o Brasil em associação com uma empresa nacional. A relação contratual foi bastante simplificada e muitos detalhes foram suprimidos, de modo a permitir o bom desempenho das atividades pelos alunos.

Apesar das dificuldades inerentes ao primeiro ano da atividade, o caso foi destrinchado pelos alunos, que se dedicaram à defesa dos interesses de cada uma das partes e se aprofundaram bastante nas questões envolvidas. De qualquer modo, a experiência foi muito importante para se apresentar a atividade à comunidade acadêmica e tentar torná-la recorrente e disponível aos futuros alunos.

Em 2006, houve um caso prático mais complexo, com maior quantidade de documentos para análise dos alunos. Talvez tenha sido o ano mais importante da atividade até o momento, não só para sua consolidação, mas também para adequação ao seu atual formato.

Tratou-se de uma discussão acerca da arbitrabilidade de conflitos societários envolvendo um sócio e uma grande empresa de capital aberto, ambos fictícios. Foi elaborado então um grande número de documentos societários, atas de assembleias e notificações.

Esse foi o ápice de documentos elaborados e, na prática, o máximo de trabalho dado aos alunos. Apesar do temor inicial de que a tarefa seria muito complexa, foi interessante verificar o esforço dos alunos e o seu empenho em compreender questões tão intrincadas e rarefeitas como aquelas ligadas ao direito societário.

Entre os ótimos resultados colhidos em 2006, está o fato de que a atividade serviu para consolidar a convicção de que os alunos não precisam ter aprendido na faculdade a questão que serve de pano de fundo da arbitragem. Basta um bom preparo acerca do instituto da arbitragem e, posteriormente, um estudo dirigido, para que as questões postas pelo problema e contidas no caso prático sejam solucionadas de alguma forma por eles.

Em 2007, 2008 e 2009, os casos seguiram os mesmos padrões de 2006, quais sejam, questões atuais e polêmicas de arbitragem. Houve muito trabalho por parte daqueles que minutaram o caso, já que não teve um caso real para servir de inspiração.

No primeiro dos anos, foram trazidas questões envolvendo direito administrativo, direito internacional privado e direito público, com a criação de um novo Estado, Cabo Leste, que passava por problemas em relação a licitações realizadas antes de sua independência. Os alunos se debruçaram com afinco sobre as questões apresentadas, entre elas questões envolvendo projetos de hospitais elaborados. Eles estranharam a 
quantidade de prova a ser produzida durante o painel arbitral, mas, infelizmente, a criação e o encaixe desta criação no âmbito do painel arbitral também faz parte da atividade. Claro, a verossimilhança deve estar presente, e o trabalho de convencimento dos árbitros é fundamental. Nem todas as situações possíveis podem ser previstas, e os grupos participantes devem estar prontos para rebater argumentos e provas com presença de espírito, já que faz parte do aprendizado vivencial apresentar reações de acordo com o papel desempenhado, uma vez que não é possível prever todos os atos que podem ocorrer durante a instrução.

Em 2008, a discussão envolveu uma sociedade existente entre duas empresas, uma de transporte e uma petrolífera. Nessa relação também foram discutidas questões de direito concorrencial, especialmente quanto à relação societária entre as empresas e a obrigatoriedade de aquisição de quantidades mínimas de combustíveis. A atividade também foi um grande sucesso. $\mathrm{O}$ esforço dos alunos demonstrou que o modelo adotado estava funcionando.

Em 2009, a discussão envolveu uma relação de consumo na aquisição de um imóvel. Foram discutidas as questões da arbitrabilidade da discussão, do cumprimento substancial de obrigações, da consignação em pagamento e da responsabilidade civil.

Felizmente o padrão estava consolidado. O mecanismo de trabalho dos alunos, o raciocínio e a lógica jurídica, com maior ou menor complexidade, também se mantêm os mesmos, com a problematização de experiências próximas da prática.

O próximo objetivo do grupo é o desenvolvimento desta atividade através de uma disputa entre instituições de ensino. A ideia está lançada, e seu desenvolvimento já começou.

\section{CONCLUSÃo}

A experiência do NEMESC merece reflexão. Nascida da necessidade, ela representa um modelo que deu certo, tentando aliar teoria e prática vivencial. A ponte entre essas duas formas de aprendizado ainda não encontrou uma fórmula adequada dentro das disciplinas dos cursos de direito. A partir do ineditismo do tema (meios alternativos de solução de controvérsias), o NEMESC desenvolve os seus estudos e as suas pesquisas com envolvimento de alunos de graduação e pós-graduação. O NEMESC, sobretudo, enfrentou o desafio de encontrar a dose adequada entre atividades teóricas e práticas, com a firme preocupação de estabelecer, na mente do aluno, um permanente diálogo entre ambas. Como demonstrado, o NEMESC, ao longo dos anos, vem buscando esta dose correta, tendo como premissa a crença na capacidade dos alunos de intelecção, investigação e resposta a problemas apresentados. Daí a convicção de que se trata de experiência a ser partilhada e multiplicada. 


\section{NOTAS}

1 Não que elas não existam. Nos cinco anos que já duram as atividades descritas neste artigo, temos tido a grata satisfação de perceber um número crescente de iniciativas pioneiras e criativas nessa área, principalmente ligadas à mediação.

2 No caso, Teoria Geral do Processo, no terceiro semestre do curso, e Direito Processual Civil I, no quarto.

3 Mediação de conflitos no palco, apresentada pelo Núcleo de Interação de Artes da Associação Interação Rede Social, em 25 de maio de 2009, no Auditório XI de Agosto. Texto de direção de Cinthia Zacarriotto. A peça versava sobre um casal que pleiteava a separação, mas ao final restou evidente a diferença entre posição e interesse, bem como os segredos que levaram as partes ao conflito, em um final surpreendente. Mais informações sobre a peça e sua autora podem ser obtidas no site: <http://www.interacaoredesocial.org>, na seção Projetos - Artes \& Cultura.

4 Cf. GARTH, Bryant G. ADR and Civil Procedure: A Chapter or an Organizing Theme?, Journal of Legal Education, v. 37, pp. 34-6, 1987.

5 Ver anexo 2.

6 Além das hipóteses forenses, em sua vivência como causídico a negociação será de suma importância. Como singelo exemplo, destaca-se que para a fixação da verba honorária em contrato é essencial que o advogado negocie valores (embora nas faculdades tal tema não seja abordado).

7 Artigo 125 do CPC: "O juiz dirigirá o processo conforme as disposições deste Código, competindo-lhe: I assegurar às partes igualdade de tratamento; II - velar pela rápida solução do litígio; III - prevenir ou reprimir qualquer ato contrário à dignidade da Justiça; IV - tentar, a qualquer tempo, conciliar as partes" (grifos nossos).

8 Os textos são escaneados e enviados no formato digital.

9 Há indicações de leitura básica, cujo teor será debatido em sala de aula, e de bibliografia complementar, para aprofundamento sobre o assunto.

10 Cada texto costuma ter entre 8 e 15 páginas; a experiência com textos mais longos e/ ou estrangeiros tem revelado menor adesão dos alunos à sua leitura.

11 Helena Mandelbaum colaborou valiosamente para essa atividade, prestando seus amplos conhecimentos como experiente mediadora ao corpo discente. Forneceu ainda para o trabalho um caso empresarial que efetivamente ocorrera, possibilitando aos alunos perceberem a amplitude da possibilidade da mediação nos mais diversos ramos.

12 Este, apesar de estar vinculado ao poder judiciário, independe da prestação jurisdicional tradicional, e sua localização é diversa do fórum tradicional.

13 Sua realização decorreu de contato com a mediadora Lia Regina Castaldi Sampaio, que de forma muito generosa e colaborativa dispôs-se a atuar para sua realização, apesar de muitas dificuldades a serem superadas para sua realização.

14 Como na Faculdade de Direito não havia os equipamentos suficientes para a apresentação de uma peça teatral, houve a adaptação do formato para compor uma leitura dramática.

15 Professora associada do Departamento de Direito Civil da Faculdade de Direito da USP.

16 Juíza titular da $2^{a}$ Vara de Família e Sucessões da Comarca de Jundiaí/SP e presidente do Núcleo de Conciliação e Mediação da APAMAGIS.

17 Ver anexo 1. 


\section{AneXo I}

\section{Lista de CASOS DO NEMESC E ÁRBITROS DO PAINEL ARBITRAL}

\begin{tabular}{|c|c|c|}
\hline ANO & CASO & ÁRBITROS \\
\hline 2005 & $\begin{array}{l}\text { COBRAFOAUTO - CONFLITO CONTRATUAL } \\
\text { ENTRE FÁBRICA DE VEÍCULOS } \\
\text { E DISTRIBUIDORA NO BRASIL }\end{array}$ & $\begin{array}{l}\text { FÁBIO NUSDEO, CARLOS ALBERTO CARMONA } \\
\text { E ANTONIO CARLOS DE ARAUUJO E CINTRA }\end{array}$ \\
\hline 2006 & $\begin{array}{l}\text { LIVRARIA LEITURA E LIVROS S.A. } \\
\text { - CONFLITO SOCIETÁRIO }\end{array}$ & $\begin{array}{l}\text { CARLOS ALBERTO CARMONA, MARCOS PAULO } \\
\text { DE ALMEIDA SALLES E FÁBIO NUSDEO }\end{array}$ \\
\hline 2007 & $\begin{array}{l}\text { CABO LESTE - CONFLITO ENVOLVENDO } \\
\text { DIREITO ADMINISTRATIVO E DIREITO } \\
\text { INTERNACIONAL PÚBLICO E PRIVADO }\end{array}$ & $\begin{array}{l}\text { CARLOS ALBERTO CARMONA, MARISTELA } \\
\text { BASSO E PAULA ANDRÉA FORGIONE }\end{array}$ \\
\hline 2008 & $\begin{array}{l}\text { BRASIL VIA LTDA. - CONFLITO ENVOLVENDO } \\
\text { DIREITO FALIMENTAR, DIREITO SOCIETÁRIO } \\
\text { E DIREITO CONCORRENCIAL }\end{array}$ & $\begin{array}{l}\text { CARLOS ALBERTO CARMONA, CARLOS ALBERTO } \\
\text { DE SALLES E PAULO FERNANDO CAMPOS } \\
\text { SALLES DE TOLEDO }\end{array}$ \\
\hline 2009 & $\begin{array}{l}\text { CONSTRUCASA - CONFLITO ENVOLVENDO } \\
\text { DIREITO DO CONSUMIDOR E } \\
\text { RESPONSABILIDADE CIVIL }\end{array}$ & $\begin{array}{l}\text { CARLOS ALBERTO CARMONA, ALBERTO DO } \\
\text { AMARAL E HERMES MARCELO HUCK }\end{array}$ \\
\hline
\end{tabular}





\section{AneXo 2}

\section{Formulário de Visitas a SETORES DE CONCILIAÇÃo}

NOME DO ALUNO:

LOCAL VISITADO:

NOME DO CONCILIADOR:

DATA: / /

SeÇÃo I - IdentificAÇÃo do CAso

1) DADOS GERAIS:

REQUERENTE:

REQUERIDO:

PROCESSO NO

AÇÃO:

DATA DE DISTRIBUIÇÃO: / /

2) QUAL A NATUREZA DA LIDE?

$\square$ CIVIL

$\square$ COMERCIAL

$\square$ CONSUMIDOR

OUTRA:

3) O VALOR DA CAUSA É:

$\square$ ESTIMADO

$\square$ REAL, R\$

4) É A PRIMEIRA VEZ QUE AS PARTES PARTICIPAM DE UMA SESSÃO DE CONCILIAÇÃO?

REQUERENTE REQUERIDO

$\square$ SIM $\square$ SIM

$\square$ NÃO $\quad \square$ NÃO

5) EM QUE FASE O PROCESSO ESTÁ?

$\square$ INICIAL POSTULATÓRIA

口 SANEADORA PROBATÓRIA

OUTRA:

SEÇÃo II - Perfil do CONCILIAdor

6) O CONCILIADOR É:

$\square$ JUIZ DO PROCESSO

$\square$ JUIZ DO SETOR DE CONCILIAÇÃO

$\square$ SERVENTUÁRIO DA JUSTIC̣A

OUTRO: 
088

: A EXPERIÊNCIA DO NÚCLEO DE ESTUdOS DE MEIOS DE SOLUÇÃO DE CONFLITOS (NEMESC)

7) QUAL O CRITÉRIO PARA A REMESSA DO PROCESSO À CONCILIAC̣ÃO?

口 ANÁLISE DO CASO CONCRETO PELO MAGISTRADO

FLUXO

OUTRO:

8) QUAL A IDADE DO CONCILIADOR?

$\square$ MENOS DE 30 ANOS

口 ENTRE 30 E 40 ANOS

口 MAIS DE 40 ANOS

9) SEXO DO CONCILIADOR:

口 FEMININO

口 MASCULINO

10) QUAL A FORMAÇÃO DO CONCILIADOR?

口 SUPERIOR INCOMPLETO

口 SUPERIOR COMPLETO

11) A FORMAC̣ÃO DO CONCILIADOR É:

口 JURÍDICA

口 NÃO-JURÍDICA. QUAL?

12) TEVE CURSO PREPARATÓRIO DE CONCILIAÇÃO/MEDIAC̣ÃO?

口 SIM, POSSUI MAIS DE 40 HORAS DE FORMAÇÃO

口 SIM, POSSUI ENTRE 20 E 40 HORAS DE FORMAC̣ÃO

口 SIM, POSSUI MENOS DE 20 HORAS DE FORMAÇÃO

$\square$ NÃO

13) HÁ QUANTO TEMPO ATUA COMO CONCILIADOR?

$\square$ MENOS DE 1 ANO

$\square$ ENTRE 1ANO E 3 ANOS

$\square$ MAIS DE 3 ANOS

14) O CONCILIADOR RECEBE REMUNERAÇÃO:

$\square$ SIM

$\square$ NÃO

$\square$ APENAS AJUDA DE CUSTO

15) O CONCILIADOR EXERCE ATIVIDADE REMUNERADA?

口 NÃO

$\square$ SIM. QUAL? 
Seção III - A dinÂmica da sessão de Conciliação

O CONCILIADOR:

16) EXPLICOU PREVIAMENTE ÀS PARTES AS REGRAS SOBRE O PROCEDIMENTO DE CONCILIACCÃO?

$\square$ SIM

$\square$ NÃO

17) FOI OBJETIVO?

$\square \mathrm{SIM}$

口 NÃO

18) FOI IMPARCIAL?

$\square$ SIM

$\square$ NÃO

19) MOTIVOU AS PARTES PARA SE EXPRESSAREM?

$\square$ SIM

$\square$ NÃO

20) UTILIZOU O ARGUMENTO DE MOROSIDADE DO JUDICIÁRIO?

$\square$ SIM

$\square$ NÃO

21) SE SIM, A CONTRIBUIÇÃO DESSE ARGUMENTO PARA O ACORDO FOI:

口 DECISIVA

口 RELEVANTE

$\square$ INDIFERENTE

22) AS PARTES UTILIZARAM ARGUMENTOS DE:

$\square$ PODER. QUAIS?

口 DIREITO. QUAIS?

口 INTERESSE. QUAIS?

23) QUANTO TEMPO DUROU A SESSÃO DE CONCILIAÇÃO?

$\square$ MENOS DE 20 MINUTOS

口 DE 20 MINUTOS A 40 MINUTOS

口 MAIS DE 40 MINUTOS

24) QUAL $O$ INTERVALO INDICADO NA PAUTA ENTRE AS CONCILIAÇÕES DESTA DATA?

15 MINUTOS

口 30 MINUTOS

1 HORA

口 SUPERIOR A 1 HORA 
090 : A EXPERIÊNCIA DO NÚCLEO DE ESTUDOS DE MEIOS DE SOLUÇÃO DE CONFLITOS (NEMESC)
25) HOUVE ATRASO NA PAUTA?
$\square$ NÃO
$\square$ SIM, MENOS DE 15 MINUTOS
$\square$ SIM, ENTRE 15 E 30 MINUTOS
$\square$ SIM, MAIS DE 30 MINUTOS

\section{Seção IV - O acordo}

26) AS PARTES ESTAVAM ACOMPANHADAS POR ADVOGADOS?

REQUERENTE REQUERIDO

$\square$ SIM $\square$ SIM

$\square$ NÃO $\square$ NÃO

27) HOUVE PROPOSTA DE ACORDO?

$\square$ SIM

$\square$ NÃO

28) SE SIM, DE QUEM FOI A INICIATIVA?

$\square$ REQUERENTE

$\square$ REQUERIDO

$\square$ CONCILIADOR

29) A PROPOSTA DE ACORDO FOI REDUZIDA A TERMO MESMO NÃO SENDO ACEITA?

$\square$ SIM

$\square$ NÃO

30) HOUVE COMUNICAC̣ÃO ENTRE AS PARTES BUSCANDO CHEGAR AO CONSENSO?

$\square$ SIM

$\square$ NÃO

31) O CONCILIADOR FAVORECEU A DISCUSSÃO SOBRE POSSÍVEIS TERMOS DE ACORDO?

$\square \operatorname{SIM}$

$\square \mathrm{NA} O$

32) SE SIM, ESTA INTERVENÇÃO FOI PARA A COMUNICAC̣ÃO ENTRE AS PARTES:

$\square$ DECISIVA

$\square$ RELEVANTE

$\square$ INDIFERENTE

\section{SEÇÃo V - SATISFAÇÃO DAS PARTES}

A CONCILIAÇÃO FOI, CONSIDERANDO OS SEGUINTES CRITÉRIOS:

1. PÉSSIMO, 2. RUIM, 3. REGULAR, 4. BOM, 5. ÓTIMO.

33) PARA O REQUERENTE, FOI 
34) PARA O REQUERIDO, FOI

35) PARA O CONCILIADOR, FOI

O REQUERENTE CONSIDERA QUE:

36) CONSEGUIU EXPRESSAR SUA VERSÃO?

$\square$ SIM

$\square$ NÃO

37) HOUVE SOLUÇÃO DOS PROBLEMAS QUE GERARAM A LIDE?

$\square \operatorname{SIM}$

口 NÃO

38) HOUVE MUDANÇA DE COMPORTAMENTO DA SUA PARTE COM A CONCILIAÇÃO?

$\square \operatorname{SIM}$

$\square$ NÃO

39) HOUVE MUDANÇA DE COMPORTAMENTO DA PARTE CONTRÁRIA COM A CONCILIAÇÃO?

$\square \operatorname{SIM}$

$\square \mathrm{NÃO}$

40) COMPREENDEU OS TERMOS UTILIZADOS PELO CONCILIADOR DURANTE A CONCILIAC̣ÃO?

$\square$ SIM

$\square$ NÃO

41) COMPREENDEU O CONTEÚDO E LIMITES DO ACORDO?

$\square \operatorname{SIM}$

$\square$ NÃO

42) FICOU EM DÚVIDA ENTRE SEGUIR A ORIENTAÇÃO DO ADVOGADO E ACEITAR OU PROPOR ALGUM ACORDO?

$\square \operatorname{SIM}$

$\square$ NÃO

$\square$ ERAM COINCIDENTES

43) TRANSFERIU A DECISÃO DE REALIZAR OU NÃO O ACORDO PARA O ADVOGADO?

$\square$ SIM

$\square$ NÃO

O REQUERIDO CONSIDERA QUE:

44) CONSEGUIU EXPRESSAR SUA VERSÃO?

$\square \mathrm{SIM}$

$\square$ NÃO

45) HOUVE SOLUCุÃO DOS PROBLEMAS QUE GERARAM A LIDE?

$\square$ SIM

$\square$ NÃO 
092 : A EXPERIÊNCIA DO NÚCLEO DE ESTUDOS DE MEIOS DE SOLUÇÃO DE CONFLITOS (NEMESC)

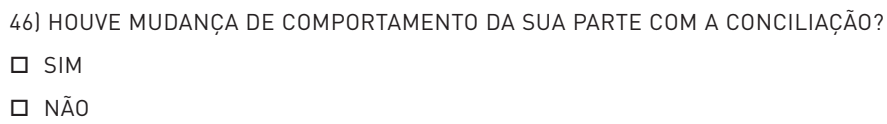

47) HOUVE MUDANÇA DE COMPORTAMENTO DA PARTE CONTRÁRIA COM A CONCILIAÇÃO?

$\square$ SIM

$\square$ NÃO

48) COMPREENDEU OS TERMOS UTILIZADOS PELO CONCILIADOR DURANTE A CONCILIAC̣ÃO?

$\square$ SIM

$\square$ NÃO

49) COMPREENDEU O CONTEÚDO E LIMITES DO ACORDO?

$\square \operatorname{SIM}$

$\square$ NÃO

50) FICOU EM DÚVIDA ENTRE SEGUIR A ORIENTAÇÃO DO ADVOGADO E ACEITAR OU PROPOR ALGUM ACORDO?

$\square \operatorname{SIM}$

$\square$ NÃO

$\square$ ERAM COINCIDENTES

51) TRANSFERIU A DECISÃO DE REALIZAR OU NÃO O ACORDO PARA O ADVOGADO?

$\square$ SIM

$\square$ NÃO

O CONCILIADOR CONSIDERA QUE:

52) PERMITIU ÀS PARTES QUE SE EXPRESSASSEM?

$\square \operatorname{SIM}$

$\square$ NÃO

53)BUSCOU A SOLUC̣ÃO DOS PROBLEMAS QUE GERARAM A LIDE?

$\square$ SIM

$\square$ NÃO

54) PODE TER OCORRIDO UMA MUDANÇA NO COMPORTAMENTO DAS PARTES A PARTIR DA CONCILIAÇÃO?

$\square \operatorname{SIM}$

$\square$ NÃO

55) A PARTICIPAC̣ÃO DOS ADVOGADOS FOI?

$\square$ POSITIVA, POIS FAVORECEU A CONCILIAÇÃO

$\square$ NEGATIVA, POIS ATRAPALHOU A CONCILIAÇÃO

$\square$ OUTRA 
56) CONHECIA O TEOR DOS AUTOS ANTES DO INÍCIO DA CONCILIAÇÃO?

$\square$ SIM

$\square$ NÃO

\section{SeÇÃo VI - Síntese Conclusiva}

57) APÓS A ANÁLISE DOS ASPECTOS GERAIS E DAS INFORMAC̣ÕES OBTIDAS, FAC̣A AS OBSERVAC̣ÕES ADICIONAIS QUE JULGAR PERTINENTE, COMENTANDO O CASO PESQUISADO.

OBS. ESTA ANÁLISE DISSERTATIVA DEVERÁ SER ENTREGUE EM FOLHA SEPARADA COM O NOME DO ALUNO.

Alameda Jaú, 1817, apto. 82 Cerqueira César - 01420-002 São Paulo - SP - Brasil casalleslauol.com.br

Rua das Uvaias, 179, apto. 62 Saúde - 04055-110 São Paulo - SP - Brasil daniela.gabbaylafgv.br

Rua Avanhandava, 103, apto. 10 Bela Vista - 01306-000 São Paulo - SP - Brasi ericab.silvalauol.com.br
Rua Dom Duarte Leopoldo, 202, apto. 132 Cambuci - 01542-000 São Paulo - SP - Brasil fetartucelauol.com.br

\section{Carlos Alberto de Salles}

MESTRE E DOUTOR EM DIREITO PELA Universidade de SÃo Paulo (USP)

PROFESSOR DOUTOR DO DEPARTAMENTO DE DIREITO PROCESSUAL DA Faculdade de Direito da Universidade de SÃo Paulo (FDUSP)

Promotor de Justiça em São Paulo

\section{Daniela Monteiro Gabbay}

MESTRE E DOUTORANDA EM DIREITO PROCESSUAL PELA Universidade de SÃo PAULo (USP)

PESQUiSAdORA E PROFESSORA DA CLÍNICA DE MEDIAC̦ÃO DIREITO GV

Fox International Fellow pela Universidade de Yale (EUA)

ADVOGADA

\section{Érica Barbosa Silva}

MESTRE E DOUTORANDA EM DIREITO PROCESSUAL PELA UniversidAde de SÃo PAUlo (USP)

PESQUISADORA E PROFESSORA DE PROCESSO CIVIL E HERMENÊUTICA JURÍDICA

Membro do Instituto Brasileiro de Direito Processual (IBDP)

Tabeliã de Notas e Oficiala Registradora em Säo Paulo

\section{Fernanda Tartuce}

MESTRE E DOUTORANDA EM DIREITO PROCESSUAL PELA UNIVERSIDADE de São Paulo Professora e sub-COORdenadora em Cursos dE ESPECIALIZAÇÃO EM DIREITO CIVIL E PROCESSUAL CIVIL

PROFESSORA DE DIREITO PROCESSUAL E PRÁTICA CIVIL EM CURSOS PREPARATÓRIOS PARA CARREIRAS JURÍDICAS

ADVOGADA ORIENTADORA DO DEPARTAMENTO JURÍDICO do Centro Acadêmico XI de Agosto (USP)

Membro do Instituto Brasileiro de Direito de Família (IBDFAM) E do InSTITUTO BRASILEIRO DE DIREITO PROCESSUAL (IBDP)

ADVOGADA E MEDIADORA 
094 : A EXPERIÊNCIA DO NÚCLEO DE ESTUdOS DE MEIOS DE SOLUÇÃO DE CONFLITOS (NEMESC)

\section{Luis Fernando Guerrero}

Rua Alsacia, 230 Jardim Aeroporto - 04630-010

São Paulo - SP - Brasil

lfgladinamarco.com.br

MESTRE E DOUTORANDO EM DIREITO PROCESSUAL PELA UniVersidade de SÃo Paulo (USP)

ESPECIALIZADO EM MEDIACÃA E NEGOCIACTĀO PELA NoRThWEstern University (EUA)

Advogado

\section{Marco Antônio Garcia Lopes Lorencini}

Rua Caraíbas, 1199, apto. 101-A

Perdizes - 05020-000

São Paulo - SP - Brasil

marco.lorenciniagmail.com

ESPECIALISTA EM DIREITO INTERNACIONAL pela Universidade de São Paulo (USP)

MESTRE E DOUTOR DIREITO PROCESSUAL PELA Universidade de SÃo PaUlo (USP)

PESQUISADOR E PROFESSOR UNIVERSITÁRIO

Membro do Centro Brasileiro de Estudos e Pesquisas Judiciais (CEBEPEJ)

Advogado 